\title{
HEALTH AND SOCIAL ASPECTS OF CONDUCTING SPORTS ACTIVITIES
}

\section{Jelka Gošnik, Krešimir Žažar}

\begin{abstract}
Summary: Engaging in sports activities certainly possesses multiple facets. Notwithstanding the apparent health dimension, doing sports is a pertinent social activity, and is of particular importance for the young population, including students. The main aim of this paper is to present the key contours of sports performance of the student population in Zagreb. The focus is on the examination of the following three aspects: self-estimation of (non)obtained sport skills and capabilities, attributes of health condition and attitudes towards sports as a social activity. The empirical analysis is based on survey data gathered in February 2016 on a non-probable occasional sample $(N=2400)$ that comprised attendants of mandatory physical education courses at the Faculty of Humanities and Social Sciences (of the University of Zagreb) and the Faculty of Science (of the University of Zagreb). The diversity of fields of study allows for interesting comparisons among students of different study groups. Despite certain slight differences, preliminary findings indicate quite a poor general engagement in sports activities and a relatively weak level of attained abilities. At the same time, sport is considered as a valuable activity in itself, which also contains the important social dimension of nurturing friendship and connecting with other people. In conclusion, the necessity for the systematic organization of sports activities and their more intensive incorporation in the academic environment, school system and at different societal levels, is emphasized. Besides, the need of sensitizing students, the young population and overall public about the importance of doing a sport, recreation and physical activity, also of pursuing a healthy life-style, is underlined. The urgency of multidisciplinary scientific inquiry of sport is highlighted, as well.
\end{abstract}

Key words: physical exercise, students, questionnaire, social dimension of sports

Introduction: Sport represents an enormously important domain in contemporary societies. It is a highly complex, multifaceted phenomenon that requires a multidisciplinary scientific approach. Alongside other dimensions, sport comprises the health and social dimension, which is the focus of this paper. As a type of recreational, physical activity, sport plays a crucial role in preserving a person's health condition. The performance of sport activities prevents widespread obesity, heart and cardiovascular diseases, as well as conveys other positive impacts on health, development of motor skills and general well-being of a person (Delaney, Madigan, 2015:117-143). A drawback of doing sports is the risk of injuries that often occur and stress related to competitive situations, intertwined with huge expectations of superior results (Delaney, Madigan, 2015:133-139). Conceived as a social phenomenon, sport can be depicted in positive and negative terms. Regarding the latter, it has often been employed as a tool of imposing particular cultural patterns, as support of nationalism and racism and a form of gender discrimination (Centre for Leisure \& Sport Research, 2002:3; Jarvie in Craig, Beedie, 2008:115; also Penney, 2002), it has been intertwined with political and hegemonic power (Houlihan, 2002; Craig, Beedie, 2008:125). On the other hand, sport reflects a dozen of positive attributes, such as: capability of overcoming social exclusion (Centre for Leisure \& Sport Research, 2002:2), i.e. it contributes to social inclusion and promotion of individuals from deprived and marginalized social groups (Levine, 2010; Delaney, Madigan, 2015:141), and consequently conduces to social cohesion (Craig, Beedie, 2008:118). Furthermore, some studies report that practising sport activities generates positive personal attributes (Delaney, Madigan, 2015:118-121), and that taking part in certain competitive sports (for instance rugby) has favourable effects in developing entrepreneurial ethos (Nikolašević, 2011). In sum, sports certainly possesses transformative capacities towards building an enhanced society.

Engaging in physical activity is of immense importance for children, adolescents and the youth, as the habit of exercising and the attitude towards physical activities tend to be continued throughout a lifetime. In the context of Croatian society, a more comprehensive insight into health and social aspects of pursuing sports activities is still missing. Over the years (during 1970s and 1980s), the examination of sport as a social phenomenon was firmly affined to kinesiology experts, while the more recent research interest of sociologists has been focused on topics like football fans behaviour (primarily violent), subculture of football fans and akin themes (Perasović, Bartoluci, 2007). Among quite rare studies on youth and sport-related topics, the research of Bjelajac (2006) ought to be men- 
tioned, on the position of sports within the leisure time activities among secondary school pupils, and the study of Andrijašević and others (2005) which identified gender differences in a self-evaluation of health related to sport experiences among students of the University of Split. When focusing on the student population, there is a lack of detailed knowledge on diverse features of their sport performance.

Aim and Objectives of the Study: The crucial objective of this empirical contribution is to reveal the scope of attained sports and motoric skills, examine habits and attitudes towards healthy life-styles and inquire into the attitudes of students' population in Croatia towards certain social aspects of sport. This research is confined to a sample of the target population of the University of Zagreb, focusing on the self-estimation of (non)obtained sport skills and capabilities, attributes of health condition and attitudes towards sports as a social activity.

Methodology: The empirical analysis is based on survey data gathered in February 2016 on a non-probable occasional sample $(\mathrm{N}=2400)$ that comprised attendants of mandatory physical education courses at the Faculty of Humanities and Social Sciences of the University of Zagreb (FHSS), and the Faculty of Science of the University of Zagreb
(FS). The overall sample includes 1483 respondents of FHSS and 917 of FS ${ }^{1}$. The gathered responses are presented separately for both faculties, since the diversity of fields of study allows for interesting comparisons among students of different study groups. As this survey was not undertaken directly for the purpose of the analysis that follows, possible hypotheses have not been formulated. Still, certain items in the questionnaire are relevant to the issues under consideration. This study is mainly descriptive in nature and inevitably exhibits certain epistemological limits and constraints. However, the gathered data delineate general sketches of the examined phenomenon, providing valuable insights that can be further deepened.

Results and Discussion: The first set of items is related to students' self-estimation of (non)obtained sport skills and capabilities. A relatively considerable number of respondents of FHH report that, besides regular classes at the physical education course, they never $(26,2 \%)$ exercise physical activity, alongside approx. one third that exercise several times per month, while others perform it more frequently. The students of FS are slightly more active: $17,4 \%$ of them are not involved in physical activities, one third is engaged in practising several times per month, whereas the rest of the subsample claim to be quite regularly engaged in such activities.
FHSS

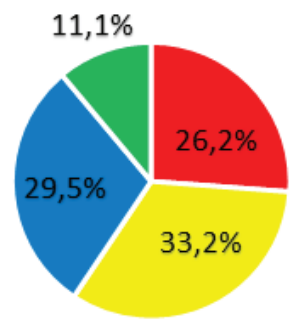

- Never

- Several times per month

- 2-3 times per week

- At least 4-5 times per week
FS

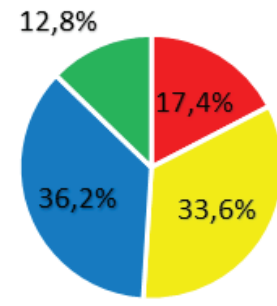

- Never

- Several times per month

- 2-3 times per week

n At least 4-5 times per week

Figure 1. Frequencies of conducting physical activities alongside obligatory faculty courses

\footnotetext{
${ }^{1}$ Both subsamples consist of predominantly female respondents: $72,8 \%$ in the case of FHSS and $63,0 \%$ of FS.
} 
There is no significant difference between the subgroups regarding their swimming skills. Roughly $40,0 \%$ of all respondents estimate themselves as 'exceptionally good' swimmers and approx. 45,0\% labelled their swimming capabilities as 'good'. However, more than $10,0 \%$ of those who estimate their swimming skills as 'average' and several students who have barely attempted to swim should raise concern. Even more concern raises the degree of alpine skiing skills. Namely, nearly two third of the respondents at both faculties assert that they have never experienced skiing, whilst less than $15,0 \%$ estimate their skills as 'good' or 'exceptionally good'. A distinctively favourable situation represents bicycle riding, since approx. $90,0 \%$ of the students claim that they perform this activity either 'good' or 'exceptionally good'.
The second section refers to particular aspects of the health condition of the target population. The students of FHSS declare themselves as cigarette smokers in considerably larger rates compared to their colleagues from FS. Whereas nearly $70,0 \%$ of the attendees of the latter institution claim that they have never smoked, the proportion of such answers of the FHSS subsample is close to $55,0 \%$. Simultaneously, less than $20,0 \%$ of students enrolled in FS smoke at least half a box of cigarettes, and there is almost one third of such respondents within the FHSS sample. The majority of smokers started smoking during their teenage years, a smaller proportion even earlier. The provided numbers, especially in the case of FHSS students, are quite troublesome, and certainly there is an urgency to introduce programmes and campaigns directed to profoundly reduce smoking.

\begin{tabular}{|l|c|c|c|c|}
\hline \multirow{2}{*}{$\begin{array}{l}\text { How many cigarettes do you smoke on a } \\
\text { daily basis? }\end{array}$} & \multicolumn{2}{|c|}{ FHSS } & \multicolumn{2}{c|}{ FS } \\
\cline { 2 - 5 } & $\mathrm{N}$ & $\mathbf{\%}$ & $\mathrm{N}$ & $\mathbf{0}$ \\
\hline I have never smoked cigarettes & 787 & $\mathbf{5 3 , 1}$ & 625 & $\mathbf{6 8 , 2}$ \\
\hline Up to half a box & 285 & $\mathbf{1 9 , 2}$ & 116 & $\mathbf{1 2 , 6}$ \\
\hline Up to 1 box & 148 & $\mathbf{1 0 , 0}$ & 57 & $\mathbf{6 , 2}$ \\
\hline More than 1, less than 2 boxes & 37 & $\mathbf{2 , 5}$ & 11 & $\mathbf{1 , 2}$ \\
\hline More than 2 boxes & 0 & $\mathbf{0 , 0}$ & 0 & $\mathbf{0 , 0}$ \\
\hline I do not smoke anymore & 222 & $\mathbf{1 5 , 0}$ & 108 & $\mathbf{1 1 , 8}$ \\
\hline Total & 1483 & $\mathbf{1 0 0 , 0}$ & 917 & $\mathbf{1 0 0 , 0}$ \\
\hline
\end{tabular}

Table 1. Smoking habits

Table 2. contains data regarding drinking habits. It attached to the 'bottle'. Beer is the most popular is discernible that a fair number of students glad- beverage, followed by wine, while shots, and parly consume alcoholic drinks, most of them less ticularly cocktails, are less consumed. In sum, the than once a week, and a significant number 1 to 3 usage of alcoholic drinks among students is quite times a week. There is no huge difference between widespread and surely requires mechanisms to mitthe two subsamples, albeit FHSS students are more igate that habit.

\begin{tabular}{|l|c|c|c|c|}
\hline \multirow{2}{*}{$\begin{array}{l}\text { How frequently do you consume alcoholic } \\
\text { drinks? }\end{array}$} & \multicolumn{2}{|c|}{ FHSS } & \multicolumn{2}{c|}{ FS } \\
\cline { 2 - 5 } & $\mathrm{N}$ & $\mathbf{\%}$ & $\mathrm{N}$ & $\mathbf{0}$ \\
\hline I do not consume them at all & 281 & $\mathbf{1 8 , 9}$ & 203 & $\mathbf{2 2 , 1}$ \\
\hline Less than once a week & 847 & $\mathbf{5 7 , 1}$ & 553 & $\mathbf{6 0 , 3}$ \\
\hline 1 to 3 times per week & 283 & $\mathbf{1 9 , 1}$ & 145 & $\mathbf{1 5 , 8}$ \\
\hline 4 to 6 times per week & 31 & $\mathbf{2 , 1}$ & 8 & $\mathbf{0 , 9}$ \\
\hline Every day & 8 & $\mathbf{0 , 5}$ & 0 & $\mathbf{0 , 0}$ \\
\hline Uncontrolled & 33 & $\mathbf{2 , 2}$ & 6 & $\mathbf{0 , 7}$ \\
\hline Total & 1483 & $\mathbf{1 0 0 , 0}$ & 917 & $\mathbf{1 0 0 , 0}$ \\
\hline
\end{tabular}

Table 2. Habits/frequencies of drinking alcoholic drinks 
Another relevant medical aspect is related to the type of job ${ }^{2}$ that students perform parallel to their academic obligations. The pattern recorded in the case of both subsamples is very akin: more than $40,0 \%$ perform a job that requires sitting, slightly above $20,0 \%$ jobs dominantly performed while standing, 6,0 to 8,0 percent of jobs are considered to be both physically intensely demanding and severely stressful. As the detected attributes surely can negatively affect students' health, there is the need to constantly improve their working environment.

It is interesting, and also rather surprising, to find that students of both faculties express certain ambivalence regarding the attitude that lessons in physical education should be a platform to discuss sexual health issues. Almost 30,0\% within both groups believe that such topics are equally important and unimportant to examine. Considerably more of them share the opinion that physical education courses should examine topics like healthy food and prevention of obesity, or the role of regular physical activity in health care. The somehow bewildering finding of undermining the importance of sexual health topics requires further examination.

Under the header attitudes towards sports as a social activity several items comprised in the questionnaire are subsumed. Students of both groups consider sport to be an important leisure time activity. More than $70,0 \%$ of FHSS respondents and above $80,0 \%$ of FS students underlined exactly that aspect. Furthermore, sport is viewed as a valuable social activity since approx. two third of FHSS, and more than $70,0 \%$ of FS respondents appraised it like a modality of spending time with friends. To a considerably lower degree, yet still notably (in both groups approx. 44,0\%), sports activities are seen as a means of obtaining new friendships. Whether the new companions share an equal worldview is less, but still (especially in the case of FS) important. The competitive aspect of sport is not particularly present, as less than $20,0 \%$ of respondents indicate this particular attribute as relevant. However, it should be noted that this motive is not central, because other factors connected to health care, maintaining fitness, good body shape and personal psychological benefits are valuated as more important. The presented data imply that sport is conceived as a pertinent social activity. Obviously, sport has a vast

${ }^{2}$ Almost $40,0 \%$ of FHSS and nearly $30,0 \%$ of FS students reported to work paid jobs during the semester. inclusive potential, the prospect of integrating an individual within a group, as well as linking diverse social groups. In the examined case of Croatian society, the urgent task is to contrive optimal ways through which this potential can be achieved.

The questionnaire also includes several claims that reflect general attitudes towards sport. The favourable comprehension of sport activities is evident. A slightly more positive estimation is registered by FS students, with only $3,5 \%$ of undecided respondents, whereas the dominant majority acclaimed the benefits of practicing sports. Among respondents from the FHSS sample 6,3\% were ambiguous, and 1,5\% did not agree with the assumption of advantages of doing sports. At the personal level, somewhat different figures appear. Namely, almost two third of FS attendees perceive physical activity as personally important in life, while $53,0 \%$ of respondents provided such an answer in the case of FHSS. Around 75,0\% of the FS sample alleged that they prefer to conduct physical activities, while such feedback occurs in approx. $65,0 \%$ cases of the FHSS sample. On the other hand, around $10,0 \%$ of FHSS students declared that they do not like to exercise physical activities in comparison to approx. 5,0\% in the other group. In short, it seems that engaging in physical activity is estimated as a positive cultural value. However, problems appear when it should be converted into concrete exercising practice.Despite certain very slight differences between the two subsamples (notably in terms of smoking and drinking alcohol behaviour, and the opinion about the relevance of physical activities), the overall preliminary findings indicate quite a poor engagement in sports activities and a relatively weak level of attained abilities and motoric skills (particularly alpine skiing, and to some extent also swimming). On the other hand, students give quite high importance to sport in general, while simultaneously not performing physical activities in practice. Hence, the pertinent task is to reconcile the detected discrepancy between the nominally accepted value of sports and the lack of its practising.

There are particular limits and constraints of this contribution. This study offers worthy, though only partial insights. Having in mind the type of the sample, the results surely cannot be generalized on the entire student population of the University of Zagreb, and the findings are especially not valid for the overall student population in Croatia. Furthermore, the list of possible important questions relat- 
ed to all the examined aspects can be considerably expanded in order to acquire a more encompassing analysis. Besides, it is necessary to implement the bivariate analysis to uncover the effects of particular independent variables on the complex issue of overall students' sports engagement. Among others factors, it ought to be examined how class position, some sport's socialisation attributes ${ }^{3}$, family and overall social background influence an individual's physical activities behaviour, as well as the general social appreciation of sport. Nonetheless, future researches also require the inspection of existing sports and recreational facilities, spatial accessibility of recreational contents (especially to inhabitants of rural areas), economic affordability of practising certain sports, availability of organized activities, competencies of trainers etc ${ }^{4}$. There is a need to explore particular cultural variables like the general position attached to physical activity in a dominant value matrix. Finally, the issue needs to be scrutinized by quantitative and qualitative methodological approaches. Afterwards, adequate programmes aiming at increasing the level of physical activities of students and the overall population, as well as promoting a healthy life-style can be introduced.

Conclusion: Bearing in mind the scarce engagement of student population in physical activities and their relatively poor level of achieved motoric skills, the necessity for a systematic organization of sports and their more intensive incorporation in the academic environment, school system and at diverse societal levels is emphasized. It is equally exigent to considerably diminish the recorded rates of smoking and consuming alcoholic drinks. Moreover, there is a need of sensitizing students, the young population and the general public about the importance of doing a sport, recreational and physical activities, as well as pursuing a healthy life-style. In order to reach these objectives, adequate targeted programs ought to be initiated. Prior to their creation, detailed scientific inquiry by diverse disciplines of sport as a complex

\footnotetext{
${ }^{3}$ For instance, how the engagement in physical and sport activities has been shaped by role models and the expectations of parents. It is recommended to consult the excellent paper by Stroot (2002) concerning this topic.

${ }^{4}$ Regarding these issues, it is advisable to see: Penney, 2002;

Centre for Leisure \& Sport Research, 2002.
}

phenomenon ought to be carried out.

\section{References:}

Andrijašević, M., Paušić, J., Bavčević, T. and Ciliga, D. (2005), Participation in Leisure Activities and Self-Perception of Health in the Students of the University of Split, in Kinesiology, 37(1): 21-31.

Bjelajac, S. (2006), Učenici i sport: komparativna analiza obalnog, zagorskog i otočkog područja županije Splitsko-dalmatinske, in Zbornik radova Filozofskog fakulteta u Splitu, Filozofski fakultet, Split. 1(1): 89-100.

Centre for Leisure \& Sport Research (2002), Count Me In. The Dimensions of Social Inclusion Through Culture and Sport (Report), Leeds Metropolitan University, Leeds.

Craig, P., and Beedie, P. (2008), Sport and Diversity: Issues of Race, Ethnicity and Disability, in Craig, P., and Beedie, P. (Eds.), Sport Sociology, Learning Matters, Exeter, pp. 110-125.

Delaney, T., and Madigan, T. (2015), The Sociology of Sports (Second Edition), McFarland \& Company, Inc., Jefferson.

Houlihan, B. (2002), Political Involvement in Sport, Physical Education and Recreation, in Laker, A. (Ed.), The Sociology of Sport and Physical Education, Routledge, London and New York, pp. 190-210.

Levine, R. F. (2010), Race, School Attachment, and the Role of High School Sports, in Smith, E. (Ed.), Sociology of Sport and Social Theory, Human Kinetics, Champaign - Windsor - Stanningley - Lower Mitcham - Auckland, pp. 115-127.

Nikolašević, M. (2011), Utjecaj sporta na razvoj poduzetništva mladih, in Učenje za poduzetništvo, 1(1): 197-201.

Penney, D. (2002), Equality, Equity and Inclusion in Physical Education and School Sport, in Laker, A. (Ed.), The Sociology of Sport and Physical Education, Routledge, London and New York, pp. 110-128.

Perasović, B., and Bartoluci, S. (2007), Sociologija sporta u hrvatskom kontekstu, in Sociologija i prostor, 45(1): 105-119.

Stroot, S. (2002), Socialisation and Participation in Sport, in Laker, A. (Ed.), The Sociology of Sport and Physical Education, Routledge, London and New York, pp. 129-147.

Corresponding author: M. Sci. Jelka Gošnik, Senior Lecturer; University of Zagreb, Faculty of Humanities and Social Sciences; Ivana Lučića 3, 10000 Zagreb, Croatia; ++385 16113 147; +385 16156879; jgosnik@ffzg.hr 